\title{
Butyrylcholinesterase nanocapsule as a long circulating bioscavenger with reduced immune response
}

Peng Zhang, Priyesh Jain, Caroline Tsao, Andrew Sinclair, Fang Sun, Hsiang-Chieh Hung, Tao Bai, Kan Wu and Shaoyi Jiang* Department of Chemical Engineering, University of Washington, Seattle, WA, 98195. *To whom correspondence should be addressed: Email: sjiang@uw.edu

\begin{abstract}
Butyrylcholinesterase ( $\mathrm{BChE}$ ) is the most promising bioscavenger candidate to treat or prevent organophosphate (OP) poisoning. However, the clinical application of BChE is limited by two obstacles: an inadequate circulation half-life and limited sources for production. Although several modification technologies including glycosylation and PEGylation have been developed to improve its pharmacokinetics, none of them have been able to outperform blood-derived native BChE. In this work, we designed a long-circulating bioscavenger nanogel by coating equine serum-derived $\mathrm{BChE}$ with a zwitterionic polymer gel layer. This zwitterionic gel coating protected BChE from denaturation and degradation under harsh conditions. Notably, the nanocapsule exhibited a long circulation half-life of $\sim 45 \mathrm{~h}$, a three-fold increase from the unmodified native version, enabling both therapeutic and prophylactic applications. In addition, the gel coating reduced the immunogenicity of equine $\mathrm{BChE}$, unlocking the possibility to use non-human derived $\mathrm{BChE}$ as an OP bioscavenger in humans.
\end{abstract}

Key words: Nanogel, butyrylcholinesterase, organophosphate, circulation, protein delivery, and immune response

\section{Introduction}

Organophosphates (OPs) are a class of highly toxic synthetic compounds frequently used as pesticides. These compounds, such as dichlorvos and parathion, exert toxicity to insects and other animals, including humans, by inactivating acetylcholinesterase (AChE) in the peripheral and central nervous systems.[1,2] This rapidly increases acetylcholine levels at cholinergic synapses and produces an acute cholinergic crisis, resulting in 
neuromuscular paralysis throughout the body and death by respiratory failure.[3, 4] Though their use as pesticides has been regulated in many countries, OPs remain one of the most common causes of poisoning worldwide. The World Health Organization attributes 200,000 deaths per year in developing countries to OP poisoning.[5] Moreover, many of the most dangerous nerve agents developed as chemical weapons are potent OPs, including soman, sarin, VX and tabun.

Although current anticholinergic antidotes can prevent lethality from OP poisoning, they are unable to mitigate many common post-exposure effects including convulsions, incapacitation, performance deficits and permanent brain damage.[6] Bioscavenger enzymes are a promising alternative treatment, as they can bind to and neutralize OP compounds in the bloodstream before the toxin reaches its physiological target.[7] Plasma-derived butyrylcholinesterase (BChE) has been widely studied as a bioscavenger due to its rapid and irreversible binding to OPs. Exogenously administered BChE from equine or human serum has been shown to protect animals from OP poisoning as well as prevent post-exposure effects.[6, 8] Human plasma-derived BChE is considered a qualified bioscavenger candidate, having an acceptable circulation half-life in vivo to fulfill its mission without causing an immune response or adverse effects.[9] However, production difficulties have hindered the clinical application of human plasma-derived BChE. An extremely large amount of outdated human plasma is needed to generate even a single dose. It has been calculated that preparing a small stockpile of plasma-derived BChE (5000 doses) would require dedicating the entire annual U.S. supply of outdated plasma to its production, at a considerable cost.[10] Genetic engineering can produce recombinant human $\mathrm{BChE}$ (rh-BChE) at a lower cost, but rh-BChE has a much shorter circulation half-life than the native enzyme.[11] Alternatively, $\mathrm{BChE}$ derived from other animal sources such as equine serum may be used to supplement human BChE, though immunogenicity challenges must first be addressed.[12]

A technique that can effectively improve $\mathrm{BChE}$ pharmacokinetics $(\mathrm{PK})$ as well as reduce its immunogenicity is clearly in demand to advance the application of enzyme-based bioscavengers. Glycosylation and PEGylation have been adopted to modify rh-BChE, but the resulting circulation half-life is still unsatisfactory.[13] PEGylation failed to improve the PK of plasma-derived native BChE.[14] Moreover, increasing evidence shows that many PEGylated protein products induce the production of anti-PEG antibodies after 
administration, challenging the future of this technology.[15-17] To the best of our knowledge, no modified $\mathrm{BChE}$ has $\mathrm{PK}$ properties superior to its natural version.

In this work, we have developed a zwitterionic nanogel encapsulation technology to modify BChE from equine serum. Zwitterionic polymers continue to attract growing attention as an important class of super-hydrophilic biomaterials, demonstrating ultra-low levels of protein adsorption and exceptional biocompatibility.[18-20] Surfaces modified with zwitterionic polycarboxybetaine (PCB) have exhibited protein adsorption below 0.3 $\mathrm{ng} / \mathrm{cm}^{2}$ from $100 \%$ blood plasma or serum.[21] In a recent study, conjugating PCB to a protein increased its stability without sacrificing its bioactivity.[22] Moreover, PCB-based nanoparticles and nanogels were shown to have a very long in vivo circulation time and not to induce a measurable antibody response in rats after repeated intravenous (IV) injections.[23, 24] Based on these findings, we hypothesized that encapsulating BChE inside a PCB nanogel could enhance its stability and shield it from recognition by the immune system. In the meantime, the porous gel network allows OP toxins to diffuse in so that these toxins can be neutralized by enzyme binding sites, enabling it to act as a long circulating bioscavenger.

\section{Materials and Methods}

\section{Materials and instruments}

Butyrylcholinesterase (BChE) from equine serum, N-Acryloxysuccinimide (NAS), tetramethylethylenediamine (TEMED), ammonium persulfate (APS), dimethyl sulfoxide (DMSO) anhydrous, bovine trypsin, bovine serum albumin (BSA), fluorescein isothiocyanate (FITC), and paraoxon-ethyl were purchased from Sigma-Aldrich, and were used as received. Carboxybetaine acrylamide (CBAA) monomer was synthesized following a published method.[25] Synthesis of carboxybetaine acrylamide crosslinker (CBAAX) is described in the supporting information.

Dynamic light scattering and zeta potential were measured using a Malvern nano zetasizer in PBS 7.4 buffer. Transmission electron microscopy was performed using a Tecnai G2 F20 Supertwin TEM, with uranyl acetate as a negative staining agent. All bioassays were done using a BioTek Cytation 3 Multi-Mode Reader.

\section{Protein encapsulation}


For zwitterionic nanogel encapsulation, $\mathrm{BChE}$ was first modified to introduce acryloyl groups onto its surface. Taking the synthesis of $n-B C h E-50-0.2 x$ as an example, the reaction was performed by dissolving $20 \mathrm{mg}$ BChE into $10 \mathrm{ml}$ 50-mM HEPES buffer ( $\mathrm{pH}$ 8.5), followed by adding $100 \mu \mathrm{l}$ of NAS DMSO solution $(20 \mathrm{mg} / \mathrm{ml})$ dropwise. The reaction was stirred at $4{ }^{\circ} \mathrm{C}$ for two hours. The polymer encapsulation was done via in situ radical polymerization by adding $400 \mathrm{mg}$ CBAA monomer, $80 \mathrm{mg}$ of CBAAX crosslinker, $10 \mathrm{ml}$ HEPES buffer, $15 \mathrm{mg}$ APS and $60 \mu \mathrm{l}$ TEMED into the former reaction solution. After stirring for another 2 hours, the reaction mixture was concentrated and washed repeatedly with PBS 7.4 using $150 \mathrm{kDa}$ molecular weight cutoff centrifugal filters. All other samples were prepared in the same way with adjusted NAS and crosslinker amounts. The protein residue activity was measured by a commercially available activity kit (Arbor assays, USA).

Samples used for in vivo tests were labeled with FITC. Native or encapsulated BChE was dissolved in $0.1 \mathrm{M}$ sodium carbonate buffer ( $\mathrm{pH}$ 9) at a protein concentration of $2 \mathrm{mg} / \mathrm{ml}$. Then, $50 \mu 1$ of a $1 \mathrm{mg} / \mathrm{ml}$ FITC DMSO solution was slowly added to each milliliter of the protein solution. The reaction was kept at $4{ }^{\circ} \mathrm{C}$ for $8 \mathrm{~h}$ in the dark. After reaction completion, the labeled samples were concentrated and washed repeatedly with PBS 7.4 using $100 \mathrm{kDa}$ molecular weight cutoff centrifugal filters.

\section{Measurements of thermal and protease resistance}

For thermal stability tests, native and encapsulated protein samples (protein concentration $1 \mathrm{ug} / \mathrm{mL}$ in 50-mM HEPES buffer, $\mathrm{pH} 8.5$ ) were incubated at $55^{\circ} \mathrm{C}$ in a water bath. At different time points, each sample was taken out and quenched in an ice bath until measurement. After the final samples were taken out at $2 \mathrm{~h}$, activities of all samples were measured using the butyrylcholinesterase fluorescent activity kit following the manufacturer's protocol. Values were recorded as percentage of each sample activity before heating.

For the protease resistance test, native and encapsulated $\mathrm{BChE}$ samples were co-incubated with bovine trypsin at $1: 1$ weight ratio at $37^{\circ} \mathrm{C}$ in 50-mM HEPES buffer, $\mathrm{pH}$ 8.5. After $0.5 \mathrm{~h}$ or $24 \mathrm{~h}$, samples were taken out and measured using the butyrylcholinesterase fluorescent activity kit.

\section{Enzyme inhibition by OP}


Model organophosphate toxin paraoxon-ethyl was used to test the binding between native $\mathrm{BChE}$ and $\mathrm{BChE}$ nanocapsules. This assay was done by mixing $\mathrm{BChE}$ protein or nanocapsule solutions (HEPES, $\mathrm{pH}$ 8.5) with paraoxon solutions at different concentrations. The mixture was incubated at $37^{\circ} \mathrm{C}$ for $30 \mathrm{~min}$ and residual activity was measured using the butyrylcholinesterase fluorescent activity kit.

\section{Cell culture and cytotoxicity assay}

Cytotoxicity was assessed through an MTT assay. NIH3T3 cells were seeded in a 96-well plate at a density of $2 \times 10^{4}$ cells/well and incubated overnight. The following morning, the culture medium in each well was replaced with $180 \mu \mathrm{L}$ of fresh medium. Proteins or nanogel samples $(20 \mu \mathrm{L}$ in PBS) were then added to each well. After incubation for $24 \mathrm{~h}$, the medium was replaced with $200 \mu \mathrm{L}$ fresh medium containing $20 \mu \mathrm{L}$ MTT $(5 \mathrm{mg} / \mathrm{mL}$ in PBS) and incubated for another $4 \mathrm{~h}$. Finally, all medium was removed and $150 \mu \mathrm{L} /$ well DMSO was added, followed by shaking for $15 \mathrm{~min}$. The absorbance of each well was measured at $490 \mathrm{~nm}$ with pure DMSO as a blank. Non-treated cells were used as a control and the relative cell viability (mean $\% \pm \mathrm{SD}, \mathrm{n}=3$ ) was expressed as $\mathrm{Abs}_{\text {sample }} / \mathrm{Abs}_{\text {control }} \times 100 \%$.

\section{Pharmacokinetics and biodistribution study}

The pharmacokinetics of native and encapsulated BChE was studied using Sprague Dawley rats (male, body weight 74 100 g) as an animal model. Each sample was tested in six rats to generate statistical significance. All animal experiments adhered to federal guidelines and were approved by the University of Washington Institutional Animal Care and Use Committee. For pharmacokinetic studies, each FITC-labeled protein sample was administered to the rat via tail vein injection at a dose of $4 \mathrm{mg} / \mathrm{kg}$ body weight. Blood samples were collected from the tail vein at $5 \mathrm{~min}, 6 \mathrm{~h}, 24 \mathrm{~h}, 48 \mathrm{~h}$ and $72 \mathrm{~h}$ after the injection. The blood samples were put in heparinized vials, centrifuged, and the enzyme content in plasma was estimated by fluorescence intensity. The IV injections and bleeding procedure were repeated twice, with one week between each injection.

At $72 \mathrm{~h}$ after the second injection, three rats in each group were killed and the heart, liver, spleen, lung, kidney and blood were collected for biodistribution analysis. The collected organ tissues were homogenized using a tissue ruptor, followed by centrifugation at 3200 $\times \mathrm{g}$ for $30 \mathrm{~min}$ at room temperature. The fluorescence of particles in the tissues was 
measured using a microplate reader and compared to a standard curve generated using FITC-labeled samples added to untreated homogenized tissues. Two weeks post the second injection, all other rats were killed, $5 \mathrm{~mL}$ of blood was drawn from each using cardiac punch, and serum was prepared for antibody detection assays.

\section{Enzyme-linked immunosorbent assay (ELISA)}

For ELISA experiments, $100 \mu \mathrm{L}$ antigen solution $(10 \mu \mathrm{g} / \mathrm{mL}$ of native $\mathrm{BChE})$ prepared in 0.1 M sodium carbonate buffer, $\mathrm{pH} 9.5$, was used to coat each well of the 96-well plates. During the coating procedure, plates were incubated at $4{ }^{\circ} \mathrm{C}$ overnight. After removing antigen solutions, the plates were washed five times using phosphate-buffered saline washing buffer and then filled with blocking buffer (1\% BSA solution in $0.1 \mathrm{M}$ Tris buffer, $\mathrm{pH}$ 8.0). After incubation at room temperature for 1 hour, blocking buffer was removed and all wells were washed another five times. Serial dilutions of rat sera in PBS containing $1 \%$ BSA were added to the plates $(100 \mu \mathrm{L} /$ well $)$, which were incubated for $1 \mathrm{~h}$ at $37^{\circ} \mathrm{C}$. The plates were then washed five times. Goat anti-rat IgM or IgG conjugated to horseradish peroxidase (HRP) (Bethyl labs, USA) was used as the secondary antibody for detection of IgM and IgG. After adding the secondary antibody, plates were incubated at room temperature for 1 hour, and then washed five times before the addition of 100 $\mu \mathrm{L} /$ well HRP substrate 3,3',5,5'-Tetramethylbenzidine (TMB, Bethyl labs). The plates were shaken for $15 \mathrm{~min}$ and $100 \mu \mathrm{L}$ stop solution $\left(0.2 \mathrm{M} \mathrm{H}_{2} \mathrm{SO}_{4}\right)$ was added to each well. Absorbance at $450 \mathrm{~nm}$ (signal) and $570 \mathrm{~nm}$ (background) was recorded by a microplate reader. Pre-bleeding sera were used as negative control for all ELISA detections. The

positive signal was defined as absorbance significantly larger than corresponding negative control.

\section{Statistics}

Student's t test was chosen to compare two small sets of quantitative data when data in each sample set were related, with $\mathrm{P}<0.05$ being considered as statistically significant.

\section{Results and Discussion}

To coat the surface of $\mathrm{BChE}$ with a zwitterionic polymer gel, the protein was first chemically modified to introduce surface acryloyl groups, enabling carboxybetaine acrylamide (CBAA) monomer and crosslinker (CBAAX) to be grafted from the surface using free radical polymerization. As shown in Scheme 1, this process covered the 
enzyme with a non-fouling PCB hydrogel layer. This gel capsule was designed to shield $\mathrm{BChE}$ from premature proteolysis and immune system recognition while simultaneously allowing OP toxins to diffuse in for neutralization by enzyme binding sites. By adjusting reaction feed ratios, both the number of polymer-protein conjugation sites and thickness of the hydrogel layer could be adjusted. The number of acryloyl groups anchored on the protein surface, which corresponds to the conjugation sites connecting the protein and polymer shell, was adjusted by changing the feed ratio of NAS and BChE. The physical properties of nanogel bioscavengers prepared under different conditions are listed in Table 1. Sample names are assigned as n-BChE-a-bx, where a denotes the molar feed ratio between NAS and protein in the acrylation step, and $\mathbf{b}$ designates the crosslinker content during polymerization. Dynamic light scattering measurements confirmed the formation of nanogels, as the encapsulated $\mathrm{BChE}$ increased in hydrodynamic size compared to the unmodified enzyme. The activity of the enzyme was well maintained at around $90 \%$ even when it was conjugated with up to 30 acryloyl groups per subunit. We tuned the crosslinker concentration to control the size of the nanogels, and found $10 \%$ and $20 \%$ crosslinker content to result in hydrodynamic nanocapsule sizes of $\sim 20 \mathrm{~nm}$ and $\sim 30 \mathrm{~nm}$, respectively. The dry size of $\mathrm{n}-\mathrm{BChE}-50-0.2 \mathrm{x}$ was measured by transmission electron microscopy (TEM), averaging $15.8 \mathrm{~nm}$ in size (Figure 1A). Encapsulating BChE in zwitterionic nanogels also neutralized the negative surface charge of the native protein $(-19.1 \mathrm{mV})$, as measured by zeta potential. A thicker gel coat corresponded to a more neutral surface, indicating better protein surface coverage and protection.
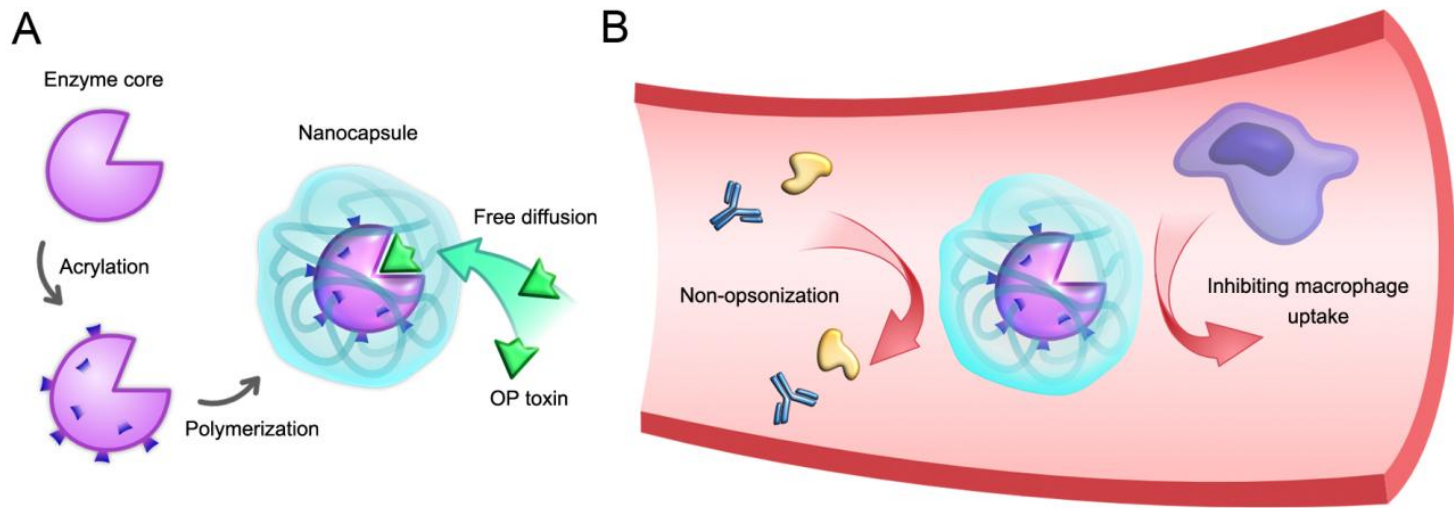

Scheme 1. (A) Fabrication of BChE nanocapsules. The OP toxins can freely diffuse through the zwitterionic gel layer and (B) The zwitterionic gel layer protects the particle from opsonization and immune cell uptake. 
Table 1 Characterization of BChE nanocapsules.

\begin{tabular}{|c|c|c|c|c|}
\hline Sample ID & $\begin{array}{l}\text { Surface vinyl } \\
\text { group number }\end{array}$ & $\begin{array}{l}\text { Hydrodynamic } \\
\text { size }(\mathrm{nm})^{\mathrm{b}}\end{array}$ & $\begin{array}{l}\text { Zeta potential } \\
(\mathrm{mV})\end{array}$ & $\begin{array}{c}\text { Residue } \\
\text { activity (\%) }\end{array}$ \\
\hline Native BChE & - & $14.5 \pm 0.8$ & $-19.1 \pm 2.9$ & $100 \pm 4$ \\
\hline$n-B C h E-5-0.2 x$ & 3.2 & $26.4 \pm 1.2$ & $-1.9 \pm 0.2$ & $92 \pm 8$ \\
\hline$n-B C h E-50-0.2 x$ & 30.3 & $30.2 \pm 2.3$ & $-5.2 \pm 0.5$ & $88 \pm 6$ \\
\hline n-BChE-200-0.2x & 45.7 & $30.6 \pm 1.8$ & $-4.9 \pm 0.3$ & $53 \pm 11$ \\
\hline n-BChE-50-0.1x & 30.3 & $20.6 \pm 3.0$ & $-10.5 \pm 1.4$ & $89 \pm 7$ \\
\hline
\end{tabular}

a Measured by MALDI-TOF MS; data expressed as number per subunit.

b Measured by dynamic light scattering.
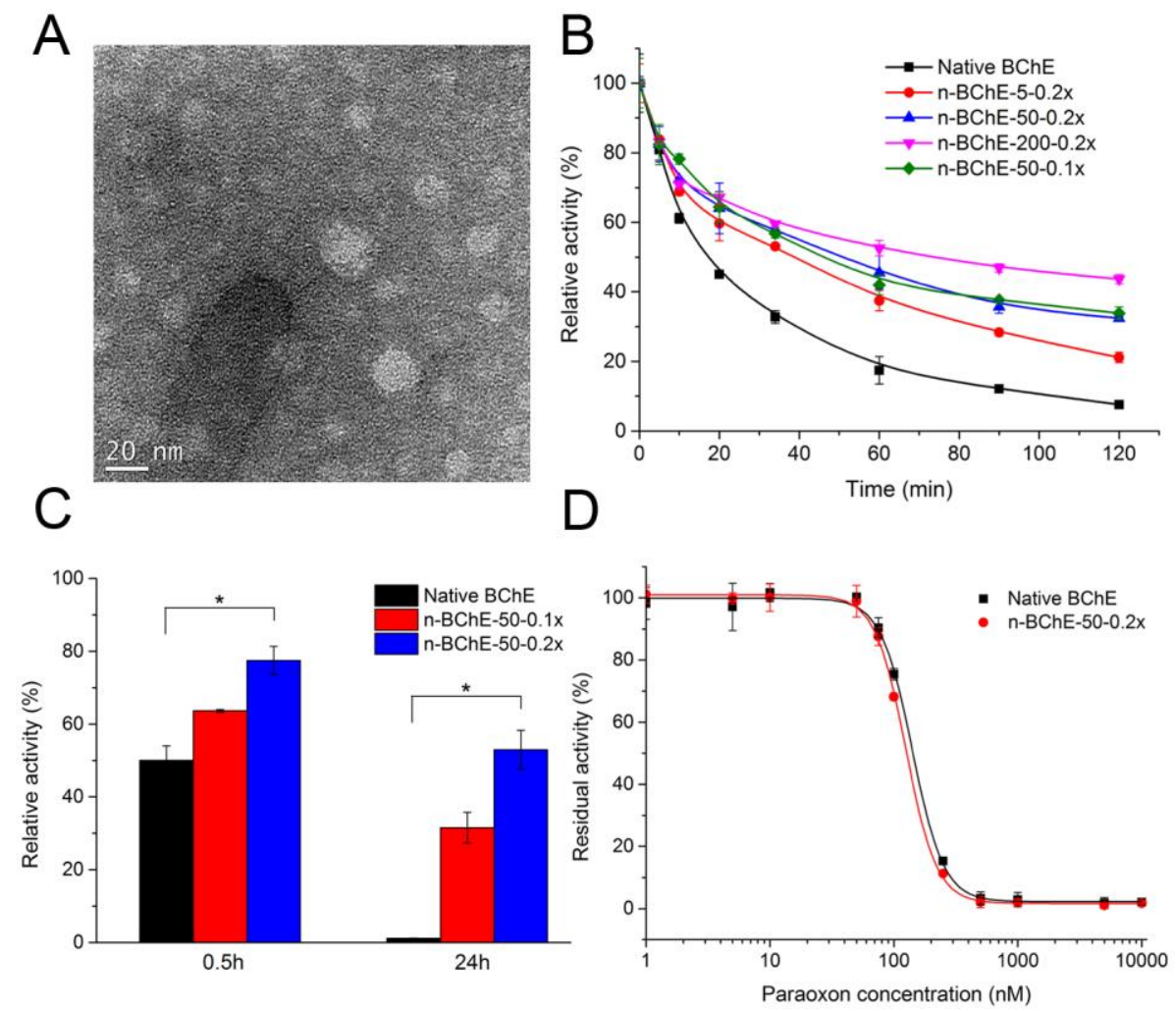

Figure 1. (A) TEM image of nanocapsules; (B) Relative activities of native BChE and nanocapsules incubated at $55{ }^{\circ} \mathrm{C}$; (C) co-incubated with trypsin $(* P<0.05)$ and (D) BChE inhibition by paraoxon-ethyl.

Due to their structural complexity, protein therapeutics are often prone to instability 
during storage, which causes great inconvenience in many applications. We performed thermal stress tests in this work to evaluate the thermal stability of enzymes prepared under different encapsulation conditions. As shown in Figure 1B, all nanocapsules retained better activity than native $\mathrm{BChE}$ when immersed in a $55^{\circ} \mathrm{C}$ water bath. This protection effect arises from a combination of two distinct mechanisms. For one, the CB monomer has substantial structural similarity to protein stabilizing agent glycine betaine. Encapsulating a protein in a PCB gel network is analogous to placing it into a highly concentrated protein stabilizing solution.[22, 24] The covalent conjugation sites between the protein and polymer gel network work alongside this stabilizing effect to provide additional protection against conformational changes,[26] which was confirmed by observing higher protein stability when a greater number of protein-polymer conjugation sites were present. The higher thermal stability extends the shelf life of this bioscavenger, and reduces the high cost of its production and use.

The in vivo stability of a therapeutic protein is not only challenged by its own structural vulnerability, but also by various proteases from organs and tissues. We chose trypsin as a model protease to evaluate the proteolytic stability of native and encapsulated $\mathrm{BChE}$ preparations. As shown in Figure 1C, after co-incubation with trypsin for $30 \mathrm{~min}$, all samples showed an initial activity drop as some BChE was enzymatically degraded. The native protein lost half of its activity, while the nanocapsules maintained $\sim 65 \%$ and $\sim 80 \%$ of their original activities depending on the nanogel thickness. Notably, while native BChE lost all activity after $24 \mathrm{~h}$ of incubation (suggesting complete digestion), the sample encapsulated in a thicker polymer layer still retained $\sim 60 \%$ of its activity. This protection from proteolysis is a major benefit of the non-fouling properties of the gel. The highly hydrated zwitterionic gel sterically hinders contact between $\mathrm{BChE}$ and proteases. Such proteolytic resistance contributes to long-term enzyme efficacy in vivo. For the following experiments, we chose $n-B C h E-50-0.2 x$ as the representative nanogel-encapsulated bioscavenger due to its balance between high residual activity and stability.

Improved stability to environmental changes and proteolytic degradation is commonly gained at the expense of bioactivity. However, $\mathrm{BChE}$ nanocapsules avoided this compromise, exhibiting high stability with minimal sacrifice to activity. To determine the in vitro OP scavenging ability of these nanocapsules, we assayed their activity following 
incubation with the model OP compound paraoxon, the active ingredient of insecticide parathion. The inhibition profiles of native $\mathrm{BChE}$ and nanogel-encapsulated $\mathrm{BChE}$ were virtually indistinguishable, with respective EC50 values of $140 \mathrm{nM}$ and $125 \mathrm{nM}$ (Figure 1D).

As the nanogel-encapsulated BChE demonstrated enhanced stability and maintained OP neutralization ability in vitro, we tested its cytotoxicity before further in vivo evaluation. Native BChE showed no cytotoxicity to NIH 3 T3 cells as expected, since it is derived from mammalian blood (Figure 2). Critically, the zwitterionic nanogel-encapsulated enzymes remained completely nontoxic, and cells retained $100 \%$ viability after incubation with $\mathrm{BChE}$ nanogels at very high concentrations, which can be attributed to the superior biocompatibility of PCB.

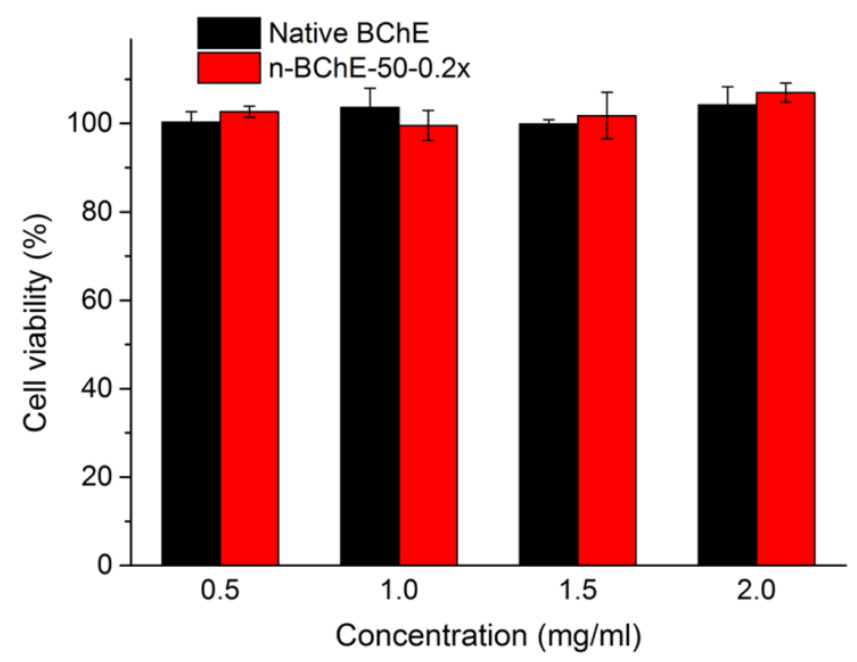

Figure 2. Cytotoxicity testing results from a MTT assay. The values represent percentage cell viability (means $\pm S D, n=3$ ).

Improving circulation half-life is the core objective of $\mathrm{BChE}$ modification technologies. Serum-derived native $\mathrm{BChE}$ is highly glycosylated, enabling it to circulate significantly longer than non-glycosylated 'naked' recombinant BChE. Thus, glycosylating rhBChE has been considered a key strategy to boost its circulation time closer to that of the native enzyme.[9] PEGylation has also been applied to modify non-glycosylated rhBChE, and resulted in a similar half-life to glycosylated rhBChE in a mouse model[27] — neither 
modification could outperform serum-derived native BChE. In addition, Saxena et al. PEGylated native glycosylated $\mathrm{BChE}$, but no improvement in circulation time was observed.[14] In this work, we studied the PK behavior of equine serum-derived $\mathrm{BChE}$ before and after zwitterionic nanogel encapsulation through repeated i.v. injections of FITC-labeled samples in healthy Sprague-Dawley rats. As shown in Figure 3A, all circulation curves fit a two compartment model. PK parameters are listed in Table 2. After the initial injection, unmodified native $\mathrm{BChE}$ exhibited an elimination half-life $\left(\mathrm{t}_{1 / 2} \beta\right)$ of $15.6 \mathrm{~h}$, in general agreement with values reported in the literature.[12] Remarkably, the circulation time of BChE nanocapsules demonstrated a threefold improvement over the native enzyme, with a $\mathrm{t}_{1 / 2} \beta$ of $45 \mathrm{~h}$. Moreover, the $\mathrm{AUC}_{\infty}$ (area under curve) of the nanocapsules was 6.7 times that of native $\mathrm{BChE}$, indicating significantly higher systemic availability. Zwitterionic polymers have a unique ability to extend the circulation time of nanoparticles beyond that of conventional biomaterials like PEG.[23, 24] The "stealth" characteristics of zwitterionic PCB and the comprehensive surface coverage of nanogel encapsulation appear to work synergistically to help these bioscavengers avoid reticuloendothelial system (RES) clearance and thus circulate for a significantly longer time.
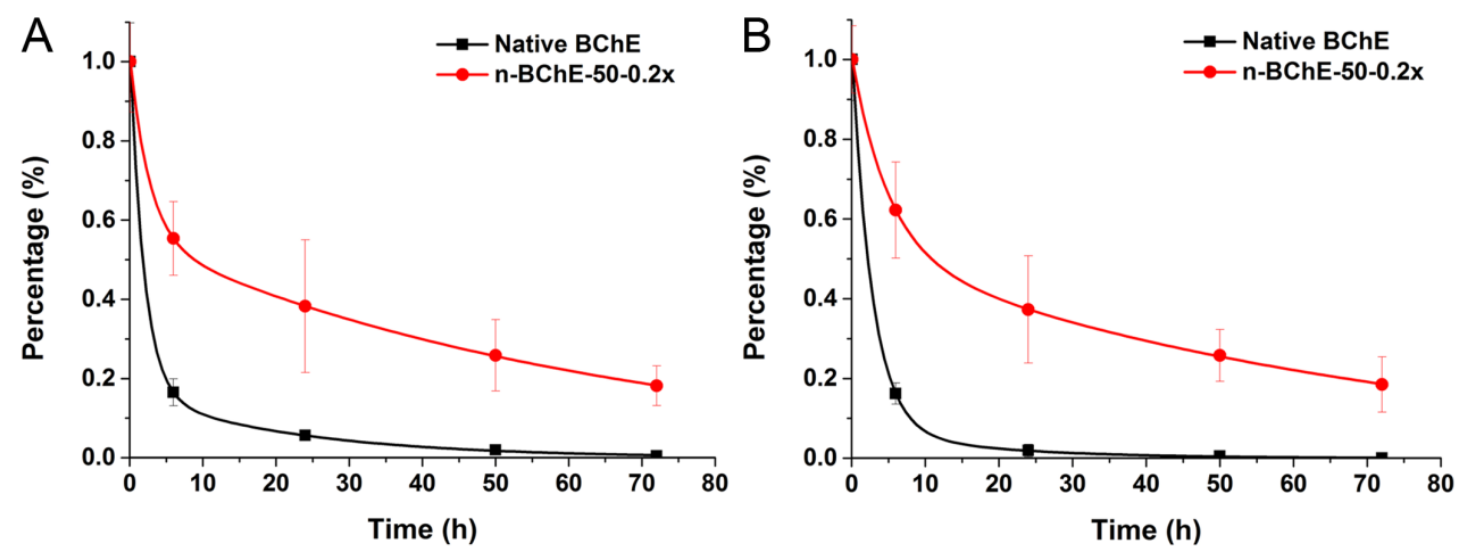

Figure 3. Blood circulation profiles of native BChE vs. nanocapsule. Circulation curves after the first i.v. administration (A) and second administration (B).

For prophylactic applications, multiple doses of bioscavenger enzymes may be needed to prolong protection against OP toxins. A second injection of encapsulated or unmodified 
$\mathrm{BChE}$ was thus given one week after the initial administration of each version, and PK profiles were evaluated as before. As shown in Figure 3B, an obvious accelerated blood clearance $(\mathrm{ABC})$ phenomenon was noted in the group treated with unmodified $\mathrm{BChE}$, with $\mathrm{t}_{1 / 2} \beta$ decreasing to $12 \mathrm{~h}, \mathrm{AUC}_{\infty}$ values dropping by a third and MRT (mean residence time) decreasing by half. This significant decrease is mainly due to the immunogenicity of equine proteins in rats. A similar phenomenon was reported for human plasma derived $\mathrm{BChE}$ administered to mice.[14] In contrast, no significant difference in the PK profile was observed between the two injections of $\mathrm{BChE}$ nanocapsules, indicating the encapsulated bioscavengers are likely to maintain their superior PK performance through repeated doses.

Table 2 PK parameters after repeated injections

\begin{tabular}{ccccc}
\hline \multirow{2}{*}{ Parameters } & \multicolumn{2}{c}{ Native BChE } & \multicolumn{2}{c}{ n-BChE-50-0.2x } \\
\cline { 2 - 5 } & Dose 1 & Dose 2 & Dose 1 & Dose 2 \\
\hline $\mathrm{t}_{1 / 2} \beta(\mathrm{h})$ & $15.6 \pm 1.2$ & $12.0 \pm 0.4$ & $45.0 \pm 4.8$ & $48.5 \pm 6.2$ \\
$\mathrm{AUC}_{\infty}(\mu \mathrm{g} / \mathrm{mL} \times \mathrm{h})$ & $344 \pm 22$ & $247 \pm 9$ & $2306 \pm 117$ & $2331 \pm 189$ \\
$\mathrm{AUC}_{0-\mathrm{t}}(\mu \mathrm{g} / \mathrm{mL} \times \mathrm{h})$ & $334 \pm 19$ & $246 \pm 6$ & $1571 \pm 86$ & $1550 \pm 103$ \\
$\mathrm{CL}(\mathrm{mL} / \mathrm{h})$ & $3.5 \pm 0.4$ & $4.8 \pm 0.3$ & $0.5 \pm 0.1$ & $0.5 \pm 0.1$ \\
$\mathrm{MRT}(\mathrm{h})$ & $16.0 \pm 1.4$ & $7.5 \pm 0.5$ & $62.8 \pm 5.3$ & $65.9 \pm 7.1$ \\
\hline
\end{tabular}

We explored the immunogenicity of this platform in further detail by collecting serum two weeks after the second injection and testing it for anti-BChE antibodies using direct ELISA. As shown in Figure 4, high titers of both IgM (titers 1:6400) and IgG (titers $1: 12800)$ were found in the group treated with native equine BChE. Glycosylated equine serum $\mathrm{BChE}$ is expected to be highly immunogenic for rats, due to differences in glycosylation and protein sequences. Likewise, unmodified $\mathrm{BChE}$ derived from other species cannot be directly used in humans, as the resulting immune response would certainly reduce its efficacy and potentially induce life-threatening anaphylactic reactions. In contrast, no $\operatorname{IgG}$ and negligible $\operatorname{IgM}$ were detected in rats treated with $\mathrm{BChE}$ 
nanocapsules, corroborating that the PCB nanogels effectively rendered the protein "invisible" to the immune system and thus mitigated antibody induction.
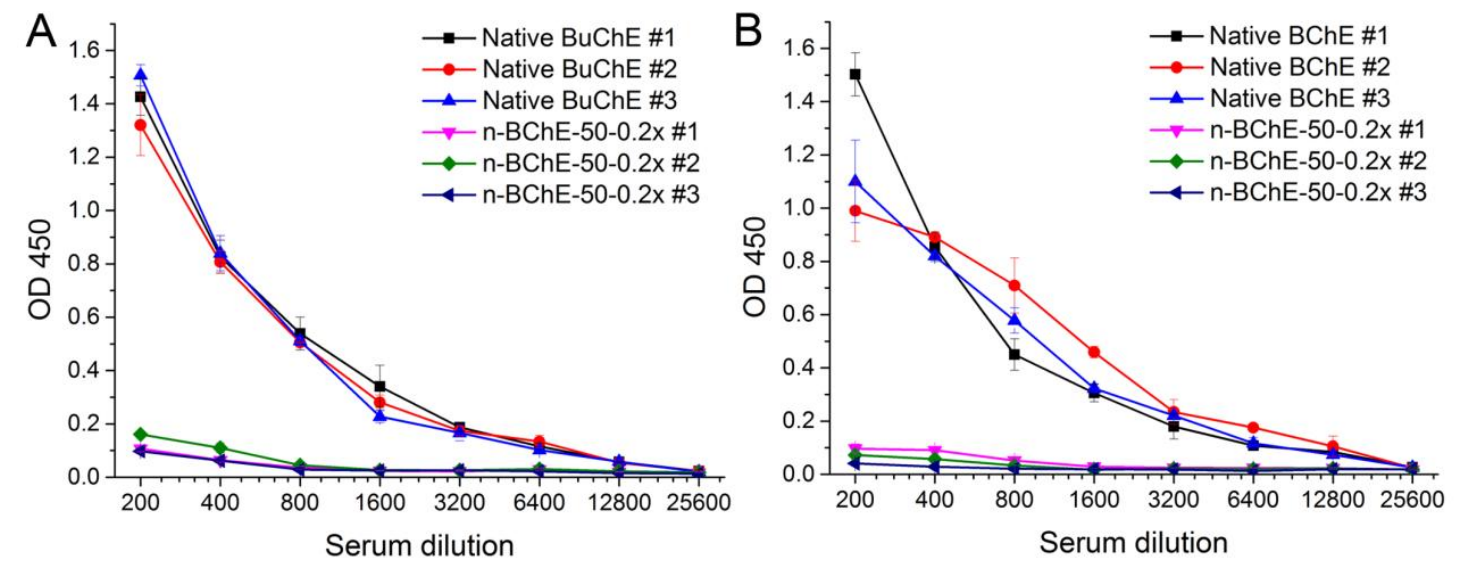

Figure 4. Detection of antibodies by direct ELISA: (A) Anti-BChE IgM and (B) Anti-BChE IgG. Serum from each rat is plotted separately.

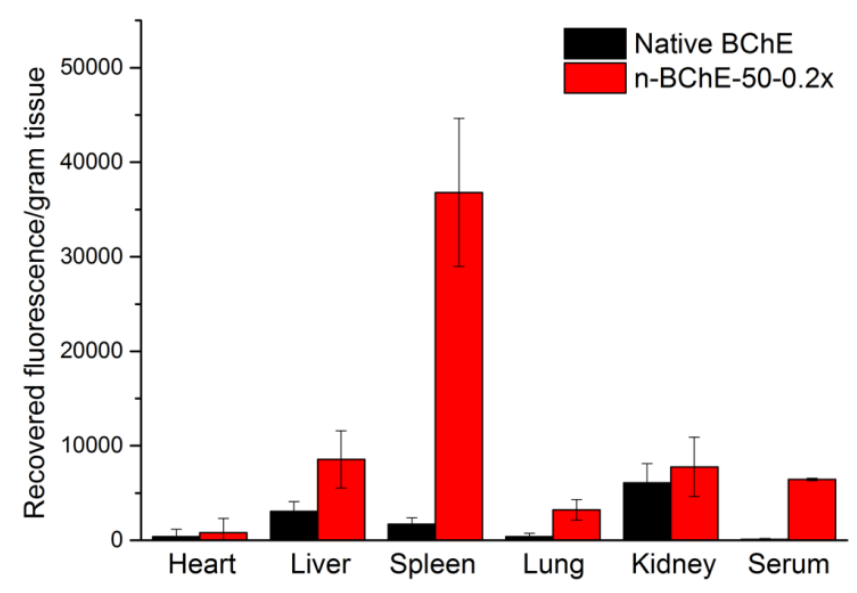

Figure 5. Biodistribution of native BChE vs. nanocapsule. Each value is averaged from three rats. SDs are shown as error bars.

To examine the biodistribution of BChE nanocapsules, we gathered blood and tissue samples from treated rats $72 \mathrm{~h}$ after the second injection for analysis. These data are presented in Figure 5 as recovered fluorescence per gram of tissue. BChE nanocapsules sustained a high serum concentration, whereas unmodified BChE was completely cleared from blood circulation. Similar to most long circulating nanoparticles, accumulation of nanocapsules was mainly found in the liver and spleen.[23, 28] We observed lower levels of organ accumulation by unmodified BChE compared with the nanocapsules three days 
after injection. This can be attributed to their differing levels of proteolytic stability. As observed from our in vitro tests, unprotected BChE was readily degraded by proteases after organ accumulation, but nanogel encapsulation partially shields BChE from protease recognition, delaying this metabolic process. The BChE nanocapsules in this work were prepared using amide-containing crosslinkers, which are expected to degrade through slow hydrolysis. If faster degradation is needed, ester or disulfide-based crosslinkers could be substituted to facilitate metabolism.

\section{Conclusions}

In summary, toxin-neutralizing enzyme $\mathrm{BChE}$, derived from equine serum, was encapsulated in zwitterionic poly(carboxybetaine) nanogels. Encapsulated BChE exhibited greater proteolytic and thermal stability than its native precursor without sacrificing its ability to neutralize OP toxins. These nanocapsules demonstrated a superior circulation half-life in vivo, outperforming the glycosylated native BChE by three times. Furthermore, repeated injections of bioscavenger nanocapsules did not induce antibody production or lose efficacy. This powerful strategy unlocks the possibility to use animal tissue derived $\mathrm{BChE}$ as supplement or replacement for the inadequate human native BChE. Enzyme bioscavengers encapsulated in zwitterionic nanogels are a promising strategy to be used in both clinical and military settings.

\section{Acknowledgment}

This work was supported by the Defense Threat Reduction Agency (HDTRA1-13-1-0044).

\section{References}

[1] R.D. Gupta, M. Goldsmith, Y. Ashani, Y. Simo, G. Mullokandov, H. Bar, M. Ben-David, H. Leader, R. Margalit, I. Silman, J.L. Sussman, D.S. Tawfik, Directed evolution of hydrolases for prevention of G-type nerve agent intoxication, Nat Chem Biol, 7 (2011) 120-125.

[2] E.X. Albuquerque, E.F. Pereira, Y. Aracava, W.P. Fawcett, M. Oliveira, W.R. Randall, T.A. Hamilton, R.K. Kan, J.A. Romano, Jr., M. Adler, Effective countermeasure against poisoning by organophosphorus insecticides and nerve agents, Proc Natl Acad Sci U S A, 103 (2006) 13220-13225.

[3] Z.Q. Pang, C.M.J. Hu, R.H. Fang, B.T. Luk, W.W. Gao, F. Wang, E. Chuluun, P. Angsantikul, S. Thamphiwatana, W.Y. Lu, X.G. Jiang, L.F. Zhang, Detoxification of organophosphate poisoning using nanoparticle bioscavengers, ACS nano, 9 (2015) 6450-6458.

[4] P.W. Elsinghorst, F. Worek, H. Thiermann, T. Wille, Drug development for the management of 
organophosphorus poisoning, Expert Opin Drug Discov, 8 (2013) 1467-1477.

[5] M. Eddleston, N.A. Buckley, P. Eyer, A.H. Dawson, Management of acute organophosphorus pesticide poisoning, The Lancet, 371 (2008) 597-607.

[6] A. Saxena, W. Sun, J.M. Fedorko, I. Koplovitz, B.P. Doctor, Prophylaxis with human serum butyrylcholinesterase protects guinea pigs exposed to multiple lethal doses of soman or VX, Biochem Pharmacol, 81 (2011) 164-169.

[7] F. Nachon, X. Brazzolotto, M. Trovaslet, P. Masson, Progress in the development of enzyme-based nerve agent bioscavengers, Chem Biol Interact, 206 (2013) 536-544.

[8] B.P. Doctor, A. Saxena, Bioscavengers for the protection of humans against organophosphate toxicity, Chem Biol Interact, 157-158 (2005) 167-171.

[9] D.G. Ilyushin, I.V. Smirnov, A.A. Belogurov, Jr., I.A. Dyachenko, T. Zharmukhamedova, T.I. Novozhilova, E.A. Bychikhin, M.V. Serebryakova, O.N. Kharybin, A.N. Murashev, K.A. Anikienko, E.N. Nikolaev, N.A. Ponomarenko, D.D. Genkin, G.M. Blackburn, P. Masson, A.G. Gabibov, Chemical polysialylation of human recombinant butyrylcholinesterase delivers a long-acting bioscavenger for nerve agents in vivo, Proc Natl Acad Sci U S A, 110 (2013) 1243-1248.

[10] B.C. Geyer, L. Kannan, P.E. Garnaud, C.A. Broomfield, C.L. Cadieux, I. Cherni, S.M. Hodgins, S.A. Kasten, K. Kelley, J. Kilbourne, Z.P. Oliver, T.C. Otto, I. Puffenberger, T.E. Reeves, N. Robbins, 2nd, R.R. Woods, H. Soreq, D.E. Lenz, D.M. Cerasoli, T.S. Mor, Plant-derived human butyrylcholinesterase, but not an organophosphorous-compound hydrolyzing variant thereof, protects rodents against nerve agents, Proceedings of the National Academy of Sciences of the United States of America, 107 (2010) 20251-20256.

[11] Y.J. Huang, Y. Huang, H. Baldassarre, B. Wang, A. Lazaris, M. Leduc, A.S. Bilodeau, A. Bellemare, M. Cote, P. Herskovits, M. Touati, C. Turcotte, L. Valeanu, N. Lemee, H. Wilgus, I. Begin, B. Bhatia, K. Rao, N. Neveu, E. Brochu, J. Pierson, D.K. Hockley, D.M. Cerasoli, D.E. Lenz, C.N. Karatzas, S. Langermann, Recombinant human butyrylcholinesterase from milk of transgenic animals to protect against organophosphate poisoning, Proc Natl Acad Sci U S A, 104 (2007) 13603-13608.

[12] L. Koetzner, J.H. Woods, Characterization of equine butyrylcholinesterase disposition in the mouse, Drug metabolism and disposition: the biological fate of chemicals, 30 (2002) 724-730.

[13] O. Cohen, C. Kronman, L. Raveh, O. Mazor, A. Ordentlich, A. Shafferman, Comparison of polyethylene glycol-conjugated recombinant human acetylcholinesterase and serum human butyrylcholinesterase as bioscavengers of organophosphate compounds, Mol Pharmacol, 70 (2006) 1121-1131.

[14] W. Sun, C. Luo, P. Tipparaju, B.P. Doctor, A. Saxena, Effect of polyethylene glycol conjugation on the circulatory stability of plasma-derived human butyrylcholinesterase in mice, Chem Biol Interact, 203 (2013) 172-176.

[15] R.P. Garay, R. El-Gewely, J.K. Armstrong, G. Garratty, P. Richette, Antibodies against polyethylene glycol in healthy subjects and in patients treated with PEG-conjugated agents, Expert opinion on drug delivery, 9 (2012) 1319-1323.

[16] J.K. Armstrong, G. Hempel, S. Koling, L.S. Chan, T. Fisher, H.J. Meiselman, G. Garratty, Antibody against poly(ethylene glycol) adversely affects PEG-asparaginase therapy in acute lymphoblastic leukemia patients, Cancer, 110 (2007) 103-111.

[17] P.E. Lipsky, L.H. Calabrese, A. Kavanaugh, J.S. Sundy, D. Wright, M. Wolfson, M.A. Becker, Pegloticase 
immunogenicity: the relationship between efficacy and antibody development in patients treated for refractory chronic gout, Arthritis Res Ther, 16 (2014) R60.

[18] L. Zhang, Z. Cao, T. Bai, L. Carr, J.R. Ella-Menye, C. Irvin, B.D. Ratner, S. Jiang, Zwitterionic hydrogels implanted in mice resist the foreign-body reaction, Nature biotechnology, 31 (2013) 553-556.

[19] R.S. Smith, Z. Zhang, M. Bouchard, J. Li, H.S. Lapp, G.R. Brotske, D.L. Lucchino, D. Weaver, L.A. Roth, A. Coury, J. Biggerstaff, S. Sukavaneshvar, R. Langer, C. Loose, Vascular catheters with a nonleaching poly-sulfobetaine surface modification reduce thrombus formation and microbial attachment, Sci Transl Med, 4 (2012) 153ra132.

[20] S. Jiang, Z. Cao, Ultralow-fouling, functionalizable, and hydrolyzable zwitterionic materials and their derivatives for biological applications, Advanced materials, 22 (2010) 920-932.

[21] J. Ladd, Z. Zhang, S. Chen, J.C. Hower, S. Jiang, Zwitterionic polymers exhibiting high resistance to nonspecific protein adsorption from human serum and plasma, Biomacromolecules, 9 (2008) 1357-1361.

[22] A.J. Keefe, S. Jiang, Poly(zwitterionic)protein conjugates offer increased stability without sacrificing binding affinity or bioactivity, Nature chemistry, 4 (2012) 59-63.

[23] L. Zhang, Z. Cao, Y. Li, J.R. Ella-Menye, T. Bai, S. Jiang, Softer zwitterionic nanogels for longer circulation and lower splenic accumulation, ACS nano, 6 (2012) 6681-6686.

[24] P. Zhang, F. Sun, C. Tsao, S. Liu, P. Jain, A. Sinclair, H.C. Hung, T. Bai, K. Wu, S. Jiang, Zwitterionic gel encapsulation promotes protein stability, enhances pharmacokinetics, and reduces immunogenicity, Proc Natl Acad Sci U S A, 112 (2015) 12046-12051.

[25] Z. Zhang, H. Vaisocherova, G. Cheng, W. Yang, H. Xue, S. Jiang, Nonfouling behavior of polycarboxybetaine-grafted surfaces: structural and environmental effects, Biomacromolecules, 9 (2008) 2686-2692.

[26] W. Wei, J. Du, J. Li, M. Yan, Q. Zhu, X. Jin, X. Zhu, Z. Hu, Y. Tang, Y. Lu, Construction of robust enzyme nanocapsules for effective organophosphate decontamination, detoxification, and protection, Advanced materials, 25 (2013) 2212-2218.

[27] N. Chilukuri, K. Parikh, W. Sun, R. Naik, P. Tipparaju, B.P. Doctor, A. Saxena, Polyethylene glycosylation prolongs the circulatory stability of recombinant human butyrylcholinesterase, Chem Biol Interact, 157-158 (2005) 115-121.

[28] Q. Yang, S.W. Jones, C.L. Parker, W.C. Zamboni, J.E. Bear, S.K. Lai, Evading immune cell uptake and clearance requires PEG grafting at densities substantially exceeding the minimum for brush conformation, Mol Pharm, 11 (2014) 1250-1258. 
Table of contents graphic:

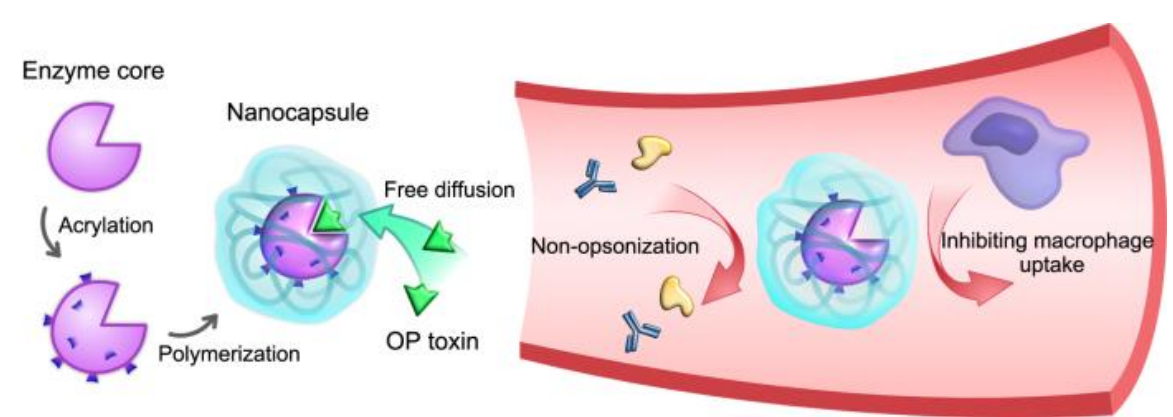

